\title{
Political Socialization and Quality of Work Life among Constituents in Davao Region, Philippines
}

\author{
Joe Van Mark B. de Gala ${ }^{1}$, Maria Darren D. Comiling ${ }^{1}$, Roche E. Novela ${ }^{1}$, \& Rico B. Maghuyop, Ed. D. ${ }^{2}$ \\ ${ }^{1}$ Political Science Discipline, University of Mindanao, Davao City, Philippines. \\ ${ }^{2}$ Professional Schools, University of Mindanao, Davao City, Philippines. \\ Correspondence: Rico B. Maghuyop, Professional Schools, University of Mindanao, Davao City, Philippines.
}

Received: January 12, 2016

Accepted: January 28, 2016

Available online: February 28, 2016

doi:10.11114/ijsss.v4i3.1423

URL: http://dx.doi.org/10.11114/ijsss.v4i3.1423

\begin{abstract}
Political socialization encompasses the overall perception of an individual in political aspects. The primary objective of this study was to identify the significant relationship of political socialization and quality of work life among the constituents in region XI. Using a descriptive-correlational method, Mean, t-Test and Pearson-r and modified survey questionnaire. Results revealed that there was a high level of political socialization and quality of work life among the constituents. Findings showed that there was no significant difference on the quality of work life among the constituents when grouped by sex and areas of abode. Furthermore, there was a significant relationship in political socialization and quality of work life among the constituents in region XI.
\end{abstract}

Keywords: political socialization, quality of work life, constituents, Davao City

\section{Introduction}

The totality of healthy experiences that individuals experience in the various aspects of their life encompasses the quality of their work life. These experiences undergone by an individual member at the work place contributes a big factor of the quality of its life.

Globally, quality of work life is a primary concern of some other countries. For instance in Canada, Canadians were trapped up in cynical argument about the future of work. Unappealing events like the rising joblessness and economic uncertainty was predicted. Also, the observers forecasted that it will result to the downsizing of the organization, the restructuring of industries and the trending of new technology. Thus, employees were treated as unnecessary. Today, however, the situations have changed. It is now becoming, a hot issue especially in business sectors. For a large and growing number of employers today, the human resource challenges are their topmost priority (Thompson, 2006).

In the Philippines, low income is one of the big issues that affect the quality of the employee's work life. Horario (2013) opined in his article in Manila Times that the minimum wage is not enough to sustain the daily needs of a common family. Take for instance, in Metro Manila, the cost of living has risen and it is not enough for the whole family members. Moreover, insufficient salary, lack of benefits, and the high cost of living are the main reasons why Filipino workers are looking and finding jobs in abroad, which extensively caused too many vacancies in jobs. These vacancies are being offered by the government to the immigrants In addition, poor job opportunity access, old and substandard modules and trainings and qualifications by the universities and colleges, technical schools and other training institutions, and over consent of a few courses contributes to pressure Filipinos away to other countries (Carcamo, 2014).

Locally, in Tagum and Davao City, the hiking of tax rates created a negative impact to the community especially on the business sectors. Based on the article made by Lacorte (2012) in Inquirer Mindanao, the real property taxes increased in some areas by up to 833 percent, thus making it difficult for many businessmen to pay their tax accountability. The escalation of tax rates certainly affects the business particularly on agricultural and commercial areas.

The researchers find the urgency to conduct this study to find out the influence of political socialization towards the quality of work life of individuals. The researchers were motivated to know if political participation was affected by the satisfactory level of individuals towards their job in their workplace. 


\subsection{Statement of the Problem}

The goal of this research was to identify the correlation concerning political socialization and quality of work life. This study pursued to answer the following problems:

1.1.1 To determine the level of political socialization among the constituents in region XI in terms of:

\subsubsection{Political Efficacy}

1.1.1.2 Political Cynicism

\subsubsection{Sense of citizen duty}

\subsubsection{Political Participation}

1.1.2 To determine the level of quality of work life among the constituents in region XI with in terms of:

\subsubsection{Job Satisfaction}

\subsubsection{Work-Family Relations}

\subsubsection{Working Environment}

1.1.3 To determine if there is significant difference on the political socialization and quality of work life among the constituents in region XI when grouped by:

\subsubsection{Sex}

\subsubsection{Areas of Abode.}

1.1.4 To determine the significant relationship between political socialization and quality of work life among the constituents in region XI.

\subsection{Null Hypothesis}

This section presents the primary assumptions of the researchers in this study.

There is no significant difference on the quality of work life among the constituents in region XI when grouped by sex and areas of abode.

There is no significant relationship between political socialization and quality of work life among the constituents in region XI.

\section{Research Methodology}

This study employed the descriptive-correlational research design. A descriptive correlational technique includes gathering data in order to determine the significance, and to what degree, a relationship exists between two or more quantifiable variables (Johnson, 2001). Therefore, a descriptive correlational technique was used to examine the relationship of political socialization and quality of work life. The researchers interacted with the research participants through the use of survey questionnaires to get the information needed for this study. This study was about the political socialization of the constituents in region XI and its relationship to their quality of work life.

\subsection{Research Subject}

The research respondents of this study were the two hundred (200) randomly chosen residences from urban and rural areas of Tagum and Davao City. The specified areas were the following: fifty (50) respondents from Barangay Visayan Village for urban area and fifty (50) respondents from Barangay Liboganon for rural area in Tagum City, and another fifty (50) respondents from Barangay MatinaAplaya for urban area and fifty (50) respondents from Barangay Acacia for rural area in Davao City. The areas were randomly selected to meet the two hundred (200) research respondents needed in this study.

\subsection{Measures}

The instrument used in this study consisted of two parts. Part one contains the political socialization which was patterned by Carlson (1975) indicated with political efficacy, political cynicism, sense of citizen duty, and political participation, with modification to fit the respondents of the study.On the other hand, part two contains the quality of work life which was patterned by NIOSH (2002) indicated with job satisfaction, work-family relations, and working environment, with modification to fit the respondents of the study. This study used 5 point likert scale.

\section{Discussion of Result}

\subsection{Level of Political Socialization among the Constituents}

Table 2 presents the level of political socialization among the respondents in region XI and it showed that the mean 
score of each indicator ranges from 3.10 to 4.20 which results to an overall mean score of 3.70 or described as high. This indicates that all perspective of the indices of political socialization of the respondents is high.

Sense of citizen duty obtained the highest mean score of 4.20 which was equivalent to high in the descriptive scale. This indicates that all perspective of the indices of political socialization of the respondents is high. On the other hand, political participation got the lowest mean score of 3.10 which was equivalent to moderate in the descriptive scale. This indicates that all perspective of the indices of political socialization of the respondents is moderate.

Based on the results the constituents in a democratic country thought voting is a duty and it is the first and foremost thing. In addition, they believe that voting is a personal choice and it can really make a difference in an election. The finding negated to the study of King (2011) that there has been a long period of decreasing in the percentage of individuals who viewed that it's their responsibility to partake in elections. Also, in communicating with other people, the constituents tend to bring about current political events from newspapers. In regards to the political participation, the result conforms to the study of Ekman and Amna (2012) that people are actively participating in political actions and activities.

Table 2. Level of Political Socialization among the Constituents in Region XI

\begin{tabular}{lll}
\hline Indicators & Mean & Verbal Description \\
\hline Political Efficacy & 3.38 & Moderate \\
Political Cynicism & 4.13 & High \\
Sense of Citizen Duty & 4.20 & High \\
Political Participation & 3.10 & Moderate \\
OVERALL MEAN & 3.70 & High
\end{tabular}

\subsection{Quality of Work Life among the Constituents}

Table 3 presents the level of quality of work life among the respondents in region XI and showing the mean scores ranging from 3.54 to 3.99 resulting to an overall mean score of 3.71 or describe as high level. This means that the quality of work life of the respondents is high.

Working environment obtained the highest mean score of 3.99 that denotes a high level. This means that the quality of work life of the respondents is high. On the other hand, work-family relations obtained the lowest mean score of 3.54 that denotes a high level. This means that the quality of work life of the respondents is high.

Based on the results, the constituents are respected at the place where they work. They also believe that the safety is the first and foremost priority in their workplace where they work hand in hand with the management to achieve the safest possible working condition. The constituents are working in an institution where the relationship is good while enjoying fringe benefits from their work. The study supported by Ugwu and Mgbo (2010) that a high quality of life in the workplace indicates to high workers satisfaction and job retention. In regards to work-family relations the demands of their job and their family matters do not interfere with each other. They find it easy to relax or pursue activities that they enjoy after an average work day. Most of the constituents consider that working in home is part of their job. The findings challenged the study of Kossek, Pichler, Bodner and Tammer (2011) that exerting to cope up the demands of work and family tends to diminish resources and augments stress and tension in the form of work-to-family conflict.

Table 3. Level of Quality of Work Life among the Constituents in Region XI

\begin{tabular}{lcc}
\hline Indicators & Mean & Verbal Description \\
\hline Job Satisfaction & 3.61 & High \\
Work-Family Relations & 3.54 & High \\
Working Environment & 3.99 & High \\
OVERALL MEAN & 3.71 & High
\end{tabular}




\subsection{Significant Difference on the Political Socialization and Quality of Work Life among the Constituents in Region XI when grouped by sex}

Presented in Table 4 is the t-test on the significant difference in political socialization and quality of work life among the constituents in region XI when analyzed according to their sex. Political socialization has an overall mean score of 3.722 on male and 3.685 for female. The computed t-test was 0.441 and the probability level was 0.34 , which was greater than the 0.05 level of significance. Therefore, the null hypothesis was accepted for political socialization. It implies that grouping the political socialization of the constituents in terms of sex does not contribute to a significant difference. On the other hand, quality of work life had an overall mean score of 3.777 on male and 3.659 for female. The computed t-test was 1.19 and the probability level was 0.12 which was greater than the 0.05 level of significance. This led to the acceptance of the null hypothesis. This implies that grouping the quality of work life of the constituents in terms of sex does not contribute to a significant difference.

The results relates to the study of Schwarzer (2011) that political socialization inculcates numerous characteristics of an individual connection with its social environment. Men and women are now equally attached to its social environment that they do not differ in their viewpoint about political socialization. Furthermore, the data showed that sex did not differentiate the constituents in their view on job satisfaction, work-family relations and working environment. Likewise, the results also complies with the study of Vakta (2014) that people as a whole are the utmost key resource in a workplace since they are in charge and capable of creating valuable influence and thus they should be regarded with self-worth and veneration. Male and female workers are given equal importance in their workplace for they have the same responsibilities in their work.

Table 4. Significant difference on the Political Socialization and Quality of Work Life among the Constituents in Region XI when grouped by sex

\begin{tabular}{lccccc}
\hline Indicators & Mean & & t-Values & Probability & Decision on Ho \\
& Male & Female & & & \\
\hline Political Participation & 3.722 & 3.685 & 0.441 & 0.34 & Accepted \\
Quality of Work Life & 3.777 & 3.659 & 1.19 & 0.12 & Accepted \\
\hline
\end{tabular}

3.4 Significant Difference on the Political Socialization and Quality of Work Life among the Constituents in Region Xl when grouped by areas of abode

Presented in table 5 is the t-test on the significance on the differences in political socialization and quality of work life among the constituents in region Xl when analyzed according to their areas of abode. The political socialization had an overall mean score of 3.74 on urban and 3.664 for rural area. The computed t-stat was 0.92 and the probability level was 0.34 which was greater than the 0.05 level of significance. This made the null hypothesis to be accepted. The data implies that grouping the political socialization of the constituents in terms of areas of abode does not contribute to a significant difference.

On the other hand, quality of work life had an overall mean score of 3.753 on urban and 3.673 for rural area. The computed t-test was 0.799 and the probability level was 0.12 which was greater than the alpha level 0.05 . Therefore, the null hypothesis was accepted for quality of work life. The data shows that grouping the quality of work life of the constituents in terms of areas of abode does not contribute to a significant difference.

This affirms to the study of Odoemelan and Aisien (2013) that political socialization is a progression that inculcates the society's political culture in each members of the society. Political socialization is widely practiced to all members in the society for citizens only share the same political culture.The data further implicates that living or working in urban or rural areas does not distinguish the constituents in their analysis on job satisfaction, work-family relations and working environment. Moreover, the results affirm to the idea of Gupta (2013) that quality of work life is like an ecosystem that everyone shares a same commonality to some degree. Constituents in urban and rural areas share a common viewpoint on the quality of their work life for they share a commonality of culture to some extent for they are all citizens of our country. 
Table 5. Significant difference on the Political Socialization and Quality of Work Life among the Constituents in Region XI when grouped by areas of abode

\begin{tabular}{lccccc}
\hline Indicators & Mean & & t-Values & Probability & $\begin{array}{l}\text { Decision on } \\
\text { Ho }\end{array}$ \\
& Urban & Rural & & & Accepted \\
\hline Political Participation & 3.74 & 3.664 & 0.92 & 0.34 & Accepted \\
Quality of Work Life & 3.753 & 3.673 & 0.799 & 0.12 & \\
\hline
\end{tabular}

\subsection{Correlation between Measures}

Table 6 reveals the relationship between political socialization and quality of work life among the constituents in region $\mathrm{Xl}$. The data showed that political socialization and quality of work life with an r-value of 0.452754 and a probability value of 0.0499 had a significant relationship. Results further imply that the null hypothesis of no significant relationship that was formulated and tested at 0.05 level of significance between political socialization and quality of work life is rejected.

This means that the political perspective of an individual can be influenced and developed by its workplace environment. An individual's political opinion, sentiments and reactions may somehow be relied or affected by the quality of the status of his or her job. This further implies that workplace enhances and encourages an individual's participation on higher perspective such as political matters.

Tasks, obligations and responsibilities at workplace develops a person's abilities and skills as an individual as well as his or her engagement in group dynamics wherein they are working in a group of individuals with a different abilities and skills with them. This enables them to test their leadership capabilities to manage a group thus it makes an individual ready for a bigger and more complex responsibilities that requires this skills such as engaging in politics or political matters. Furthermore, this idea gives an understanding that political socialization and quality of work life coincides with each other. The results conforms to the study of Schwarzer (2011) that political socialization is a psychological process and this process combines the individual's attachment in several aspects such as working environment, social environment, and quality of work life. This process influences the attitudes, $\mathrm{t}$ haviors, and participation of an individual towards its workplace. It implies that political socialization affects a persol s perspective about its workplace while the quality of work life affects the viewpoint of an individual towards politics.

Table 6. Significant relationship between Political Socialization and Quality of Work Life among the Constituents in Region XI

\begin{tabular}{llll}
\hline Variables & Pearson r & Probability & Decision on Ho \\
\hline Political Socialization & 0.452754 & 0.0499 & Rejected \\
Quality of Work Life & & & \\
\hline
\end{tabular}

\section{Conclusion}

Individuals are instated into the political culture of their own nation with the political socialization process. The result of this study revealed a high level of political socialization and quality of work life among the constituents in region XI. Workplace condition and environment may affect a person's political engagement. The level of engagement of an individual to its workplace may have a connection that affects its political standpoint or view and boost its political appetite. Workplace of a society as a whole may also determine its political dynamics.

This study revealed a no significant difference on the quality of work life among the constituents in selected cities meaning that constituents either male or female, residing on urban or rural area, have no difference in the quality of their work life. Likewise, there is a significant relationship between political socialization and quality of work life among the constituents in selected cities. It proves that the constituent's political socialization has a relationship with the quality of their work life. Their perception in politics is affected by their satisfaction in the quality of their workplace.

\section{Recommendations}

Based on the aforementioned findings and conclusions of the study, the following recommendations are given: 
Government officials, either local or national, may always consider the opinions, sentiments and reactions of their constituents. Their performance in politics affects the political socialization of their constituents. They may maintain a good morale such as integrity, honesty and credibility in order to have a good performance in their political affairs which are always been in the center of interest of their constituents. A good public official serves as a role model to its constituents thus improving their trust and confidence to the government.

Constituents may always evaluate their quality of work life wherever or whatever jobs or professions they have. The quality of their work life has a significant relationship to their political socialization. In a workplace, people are given responsibilities and tasks while working with different individuals. It enhances their participation and decision-making capabilities as an individual and as a group. A good participation in workplace encourages and develops an individual to participate in a bigger prospective such as political matters. To have a good quality of work life, an individual must have a positive outlook on its job satisfaction, well-balanced work-family relations, and a benevolent working environment.

University of Mindanao Administrators, Faculty and Staff may emphasize to the student the importance of political socialization as well as ensuring that they are well-equipped and ready for their future professions. Student may always be reminded on their duties as a citizen of our country. It may be inculcated to them the importance of political participation and most of all, their right to suffrage wherein they can exercise their right to vote. On the other hand, students may be prepared for their future career. They may be well-equipped with knowledge, professionalism and work ethics while undertaking their different courses so that they will be ready for their profession when they graduate. A good preparation ensures that they have a good quality of work life whenever and whatever work or job they have.

It is also highly recommended that another research of the same nature may be conducted in order to validate the findings of this study, or that other variables may be included that affect political socialization and quality of work life.

\section{Acknowledgments}

This work would not have been possible without the underlying support of the people around us. Our heartfelt gratitude goes to everyone whose relentless belief in our capabilities to the completion of this undertaking. To University of Mindanao Research and Publication Center for the support of this endeavor. To Dr. Gerlieta S. Ruiz and Dr. Evangeline M. Guinto, and Prof. Luzviminda T. Orilla for encouraging us in disseminating the research findings through publication.

\section{References}

Carcamo, D. (2014). Lack of incentives, low wages blamed for entry of foreign workers. Retrieved January 7, 2015 from http://www.philstar.com/headlines/2014/01/16/1279540/lack-incentives-low-wages-blamed-entry-foreign-workers

Carlson, G. (1975). Political socialization in North America, mainly the United States, but with some reference to Canada, research studies permitting.).Open Access Dissertations and Theses. Paper 5070.Retrieved January 6, 2015 from http://digitalcommons.mcmaster.ca/opendissertations/5070

Ekman, J., \& Amna, E. (2012).Political participation and civic engagement: Towards a new typology. http://www.degruyter.com/view/j/humaff.2012.22.issue-3/s13374-012-0024-1/s13374-012-0024-1.xml

Gupta, A. (2013). Quality of Work Life and Organizational Development. Retrieved January 6, 2015 from http://omicsonline.org/scientific-reports/2167-0234-SR-687.pdf

Gupta, B., \& Hyde, A. (2013).Demographical study on quality of work life in nationalized banks. Retrieved January 21, 2015 from http://search.proquest.com/docview/1503060444/D7F9E74FFE646BDPQ/4?accountid=31259

Horario, R. (2013). Minimum wage too low? http://www.manilaTimes.net/minimum-wage-too-low/47948/

Johnson, B. (2001). Toward a new classification of non-experimental quantitative research. Retrieved January 5, 2015 from http://www33.homepage.villanova.edu/Edward.fierros/pdf/Johnson.pdf

King, V. (2011). Is there such a thing as civic duty? And do we feel it? Retrieved January 6, 2015 from http://www.bbc.com/news/uk-politics- 15763388

Kossek, E., Pichler, S., Bodner, T., \& Tammer, L. (2011).Workplace social support and work-family conflict: A meta analysis clarifying the influence of general and work-family-specific supervisor and organizational support. Retrieved June 24, 2015 from http://www.ncbi.nlm.nih.gov/pmc/articles/PMC3116443/

Lacorte, G. (2012). Realty tax ordinance becomes Tagum City poll issue, http://newsinfo.inquirer.net/285426/realty-tax-becomes-Tagum-city-poll-issue

National Institute for Occupational Safety and Health (2002).Quality of work life module: general society survey 2002.Section D. Retrieved January 6, 2014 from http://www.cdc.gov/niosh/topics/stresspdfs/qwl2010.pdf 
Odoemelam, U., \& Aisien, E. (2013).Political socialization and nation building: The case of Nigeria. Retrieved June 30, 2015 from http://eujournal.org/files/journals/1/articles/978/submission/original/978-2885-1-SM.pdf

Schwarzer, S. (2011).Political socialization as the driving factor for political engagement and political participation. http://www.elecdem.eu/media/universityofexeter/elecdem/pdfs/amsterdamwksp/Steve_Schwarzer_Political_sociali zation.pdf

Thompson, C. (2006). Implications of Work-Life Balance and Job Stress. Retrieved January 6,2015 from http:/grahamlowe.ca/documents/182/Under\%2520 Pressure\%252010-06.pdf

Ugwu, O., \& Mgbo, O. (2010).The impact of political socialization on political participation- a Nigerian view point. Retrieved January 6, 2015 from https:/www.wiloludjournal.com/pdf/socialsci/2010/44-49.pdf

Vakta, H. (2014). An empirical study on work life balance and quality of life of working women in public and private sector. http://search.proquest.com/docview/1557087916/D7F9E74FFE646BDPQ/2?accountid=31259

\section{(cc) BY}

This work is licensed under a Creative Commons Attribution 3.0 License. 